\title{
Oxygen Consumption and Ammonia Excretion of Kashgarian Loach Triplophysa Yarkandensis (Day, 1877) Under Different Body Weights
}

\author{
Li Wang ${ }^{1,3}$, Jie Wei ${ }^{2}$, Zhulan $\mathrm{Nie}^{2}$, Yajuan Liu', Zhenhua Ma ${ }^{1,3 *}$ \\ ${ }^{1}$ Tropical Aquaculture Research and Development Center, South China Sea Fisheries Research \\ Institute, Chinese Academy of Fishery Sciences, Sanya572018, P.R. China \\ ${ }^{2}$ School of Animal Science, Tarim University, Alaer, 843300, P.R. China \\ ${ }^{3}$ Sansha Meiji Fisheries Development Co., Ltd., Haikou 570311, P.R. China
}

\begin{abstract}
The oxygen consumption and ammonia excretion of Kashgarian loach Triplophysa yarkandensis (Day, 1877) under different body weights were studied in laboratory condition. The specific oxygen consumption rate (SOC) and specific ammonia excretion rate (SAE) decreased with increasing body weight, while the total oxygen consumption rate and total ammonia excretion rate increased with increasing body weight. The relationship between specific oxygen consumption rate and body weight $(x)$ can be expressed as SOC $=-0.246 \operatorname{Ln}(x)+0.8395\left(R^{2}=0.965\right)$, and the relationship between specific ammonia excretion rate and body weight can be expressed as $S A E=-0.1252 x+2.5558\left(R^{2}=0.9326\right)$. Results from the present study provide fundamental information on the routine metabolic requirements of T.yarkandensis. Such information may enhance the effectiveness of intensive rearing procedures in T.yarkandensis, and the success of live fish transportation.
\end{abstract}

Keywords: Oxygen consumption; Ammonia excretion; Body Weight; Kashgarian loach; Triplophysa yarkandensis

\section{INTRODUCTION}

A measurement of the metabolism of fish is necessary in order to estimate the requirements for promoting and sustaining growth [1]. Studies on oxygen consumption and ammonia extraction in fish can directly reflect the regularity of metabolism, and can also reveal the physiological and living conditions of fish $[2,3,4,5]$. In intensive aquaculture, such measurement is also critical to control the water quality and maximize the production potential of recirculation systems [6].

Kashgarian loach Triplophysa yarkandensis belongs to the family of Cobitidae is one of the native freshwater species widely distributed in the Tarim River Basin in North-West China[7]. As one of the most important commercial fishery species, the growth of T.yarkandensis is faster, and the size is bigger as compared to other indigenous species of cobitidae family in this area [8]. However, evidence indicates that the population of T.yarkandensis in the wild has declined dramatically as a resultof overfishing and the introduction of exotic species [9]. Because of the fast growth and high market demands, T.yarkandensis has been considered as a good aquaculture candidate. Nevertheless, artificial breeding of T.yarkandensis has not been successful. Several key aspects relating to the culture of this species are not clear. In aquaculture practices, the influence of fish body weight on the oxygen consumption and ammonia excretion rates has been drawn great attention $[4,5]$. Therefore, we conduct this study to collect the basic physiological information on T.yarkandensis. The objective of this study was to determine the oxygen consumption and ammonia excretion of T.yarkandensis under different size classes. Results from the present study will provide fundamental information on rearing of T.yarkandensis in the intensive aquaculture system and transporting live fish.

\section{Materials ANd Methods}

A total of 100 numbers of Kashgarian loach were collected from Alaer Reach of TarimRiver, Tarim River Basin $\left(40^{\circ} 26^{\prime} 22.8^{\prime \prime} \mathrm{N}, 81^{\circ} 09^{\prime} 16.3^{\prime \prime}\right.$ E) and transported to the School of Animal Sciences, Tarim University, P.R. China. Experimental fish were divided into five size classes according to the 
wet body weight (Table 1), and were acclimated separately in five $100 \mathrm{~L}$ fiberglass tanks for four weeks before oxygen consumption and ammonia excretion studies were conducted. During acclimation, fish were fed twice per day with a commercial carp feeds (Carp 5513, KexinAquaFeed, P.R.China). The acclimation tanks were siphoned daily to remove uneaten feed and feces. The daily water exchange rate was maintained at $40 \%$ tank volume during acclimation.During the acclimation, rearing environment was simulated according to the natural environment in Alaer Reach of Tarim River. The water temperature was maintained at $20{ }^{\circ} \mathrm{C}, \mathrm{pH}$ was controlled at 7.2, and the dissolved oxygen in the acclimation tank was $>6 \mathrm{mg} \mathrm{L}^{-1}$. Feeding was stopped 24 hours before the measurements were conducted.

Table 1. Size Class of Kashgarian loach Triplophysa yarkandensis

\begin{tabular}{|l|l|l|}
\hline Size Class & Minimum body weight $(\mathrm{g})$ & Maximum body weight $(\mathrm{g})$ \\
\hline $\mathrm{C} 1$ & 1.09 & 1.33 \\
\hline $\mathrm{C} 2$ & 1.34 & 1.69 \\
\hline $\mathrm{C} 3$ & 3.87 & 4.78 \\
\hline $\mathrm{C} 4$ & 13.49 & 13.78 \\
\hline $\mathrm{C} 5$ & 18.23 & 18.56 \\
\hline
\end{tabular}

Twenty-five intermittent-flows through respirometer chambers were made according to Forstner (1983) and Dalla Via (1987) to measure oxygen consumption and ammonia excretion [10,11]. Each respirometer chamber was approximately $500 \mathrm{~mL}$ with an air-tight rubber lid. The respirometers chambers were big enough to allow the fish to move freely but not swim actively, characterizing an uncontrolled but minimum activity (routine metabolism). The temperature was maintained at $20{ }^{\circ} \mathrm{C}$, and the light intensity in the respirometer chamber was $<500$ lux throughout the experimental periods. All the experimental chambers were placed into a closed environment to avoid all potential interruptions. The oxygen concentration was measured with HQ40d portable multi-parameter meter (HQ40d18, Hach, USA), and the ammonia concentration was determined by indophenol method [12]. Oxygen concentration remained above $3.5 \mathrm{mg} \mathrm{L}^{-1}$ to reduce physiological stress on fish [13].

The specific oxygen consumption ( $\mathrm{SOC}, \mathrm{mg} \mathrm{O}_{2} \mathrm{~g}^{-1} \mathrm{~h}^{-1}$ ) and specific ammonia excretion (SAE, mg N$\left.\mathrm{NH}_{3} \mathrm{~g}^{-1} \mathrm{~h}^{-1}\right)$ were calculated as follows [14]:SOC $=\Delta \mathrm{O}_{2} \times v /(m \times t), \mathrm{SAE}=\Delta \mathrm{N}-\mathrm{NH}_{3} \times v /(m \times t)$, where $\Delta \mathrm{O}_{2}$ is the change in oxygen concentration $\left(\mathrm{mg} \mathrm{O}_{2} \mathrm{~mL}^{-1}\right)$ during each test period; $\Delta \mathrm{N}-\mathrm{NH}_{3}$ is the change in total ammonia concentration ( $\mathrm{mg} \mathrm{NH}_{3}+\mathrm{NH}_{4}{ }^{+} \mathrm{mL}^{-1}$ ) during each test period; $v$ is the water volume $(\mathrm{mL}) ; t$ is the measurement interval (h); and $m$ is the wet weight of fish $(\mathrm{g})$.

The total oxygen consumption (TOC, $\mathrm{mg} \mathrm{O}_{2} \mathrm{fish}^{-1} \mathrm{~h}^{-1}$ ) and total ammonia excretion (TAE, mg N-NH fish $\left.^{-1} \mathrm{~h}^{-1}\right)$ were calculated as follows: TOC $=\Delta \mathrm{O}_{2} \times v /(f i s h \times t), \mathrm{TAE}=\Delta \mathrm{N}-\mathrm{NH}_{3} \times v /(f i s h \times t)$, where $\Delta \mathrm{O}_{2}$ is the change in oxygen concentration $\left(\mathrm{mg} \mathrm{O}_{2} \mathrm{~mL}^{-1}\right)$ during each test period; $\Delta \mathrm{N}-\mathrm{NH}_{3}$ is the change in total ammonia concentration $\left(\mathrm{mg} \mathrm{NH}_{3}+\mathrm{NH}_{4}{ }^{+} \mathrm{mL}^{-1}\right)$ during each test period; $v$ is the water volume $(\mathrm{mL}) ; t$ is the measurement interval $(\mathrm{h})$; and fish is the number of fish in each chamber (fish $=$ 1 in the present study).

In each size class, five fish were randomly collected from the acclimation tank and immediately transferred to five respirometer chambers. Fish were acclimated in the chamber individually for $24 \mathrm{~h}$ before oxygen consumption and ammonia excretion were measured. Once the measurements were conducted, the feces in the respirometer chambers were flushed out $1 \mathrm{~h}$.The oxygen consumption and ammonia excretion were measured in $1 \mathrm{~h}$ interval and were lasted for $4 \mathrm{~h}$. The lid was opened and the level of DO in the chamber was recorded as the initial value by inserting the oxygen probe into the chamber. At the same time, the initial ammonia concentration was determined by vertically inserting a 40-cm glass tube into the chamber bottom and the fetching the glass tube out by sealing the top with a thumb. After sampling, the chamber was closed and the pump was turned off. Fish were allowed to stay in the static water for an hour before the dissolved oxygen and ammonia concentration were measured.

All the data presented in this study are expressed as mean \pm SE. One way ANOVA (PASW Statistics 18.0; Chicago, IL, USA) was used to analyzed the interaction between body size and oxygen consumption or ammonia excretion in fish. When a significant effect was found, Tukey's test was performed for multiple range comparisons $(P<0.05)$. All the data were tested for normality, homogeneity and independence before ANOVA. When the homogeneity of variances was violated, a non-parametric test (the Welch test) was performed in this study. 


\section{RESULTS AND DISCUSSION}

Like most of the organisms, the respiratory rate of fish is influenced by individual size $[4,15,16,17$, 18]. Evidence indicates that before fish reach maturation, the body mass seems to contribute significantly to the oxygen consumption when fish are in the period of fast growth [19]. In the present study, body weight significantly affected the specific oxygen consumption (SOC) and total oxygen consumption (TOC) $(P<0.05)$. The SOC of $\mathrm{C} 1$ and $\mathrm{C} 2$ were significantly higher than those obtained from C3, C4 and C5 $(P<0.05$, Fig. 1). The lowest SOCs were obtained from C4 and C5 groups. The SOC of fish was not significantly different either between $\mathrm{C} 1$ and $\mathrm{C} 2$ or between $\mathrm{C} 4$ and $\mathrm{C} 5$. The relationship between specific oxygen consumption rate (SOC, $y$ ) and body weight $(x)$ in $T$. yarkandensis can be expressed as $y=-0.246 \operatorname{Ln}(x)+0.8395\left(R^{2}=0.965\right.$, Fig. 1$)$. The SOC declined with the increase in fish weights (Fig. 1). The total oxygen consumption rate (TOC) of fish increased with the increasing of fish weight (Fig. 1), and the relationship between TOC $(y)$ and body weight $(x)$ can be expressed as $y=0.7353 \operatorname{Ln}(x)+0.7926\left(R^{2}=0.9821\right.$, Fig. 1). The TOCs of fish from C4 and C5 were significantly higher than those obtained in $\mathrm{C} 1, \mathrm{C} 2$ and $\mathrm{C} 3(P<0.05)$. No significant differences were found either between $\mathrm{C} 1$ and $\mathrm{C} 2$ or between $\mathrm{C} 4$ and $\mathrm{C} 5$.

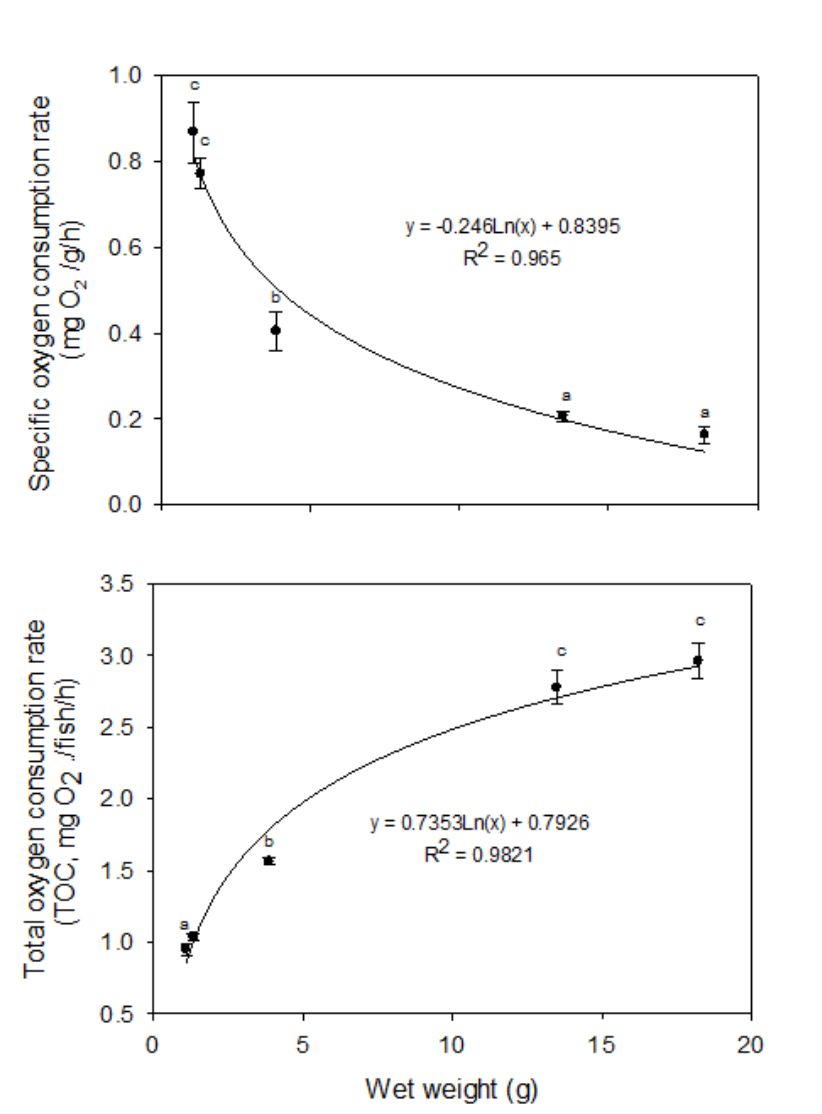

Fig1. Specific oxygen consumption rate and total oxygen consumption rate of Triplophysa yarkandensis in different size classes

Although numerous studies have been conducted in the past few decades, the dynamics of nitrogen compounds (including ammonia) in fish are still not well understood [20, 21], and there is a lack of general supporting data regarding to the actual amounts of ammonia excreted by most fish species. Such information is essential for controlling of water quality in the intensive fish production, and for developing nutritional procedures in existing systems. In the present study, the ammonia excretions of T. yarkandensis under different body weights have been successfully explored. The relationship between the specific ammonia excretion rate (SAE, $y$ ) and body weight $(x)$ in $T$. yarkandensis can be expressed as $y=-0.1252 x+2.5558\left(R^{2}=0.9326\right.$, Fig. 2$)$, and the SAE reduced with the increasing of fish weight. The SAE in $\mathrm{C} 1$ group was significantly higher than the rest group $(P<0.05)$. The SAEs from $\mathrm{C} 2$ and $\mathrm{C} 3$ were significantly higher than the results obtained in $\mathrm{C} 4$ and $\mathrm{C} 5(P<0.05)$, and no significant differences were found either between $\mathrm{C} 2$ and $\mathrm{C} 3$ or between $\mathrm{C} 4$ and $\mathrm{C} 5$. The total ammonia excretion rate (TAE) of $T$. yarkandensis increased with the increasing of body weight. The relationship between TAE $(y)$ and body weight $(x)$ can be expressed as $y=0.3132 x+3.7233\left(R^{2}=\right.$ 
0.7277, Fig. 2). The TAE of fish in $\mathrm{C} 4$ and $\mathrm{C} 5$ were significantly higher than $\mathrm{C} 1, \mathrm{C} 2$ and $\mathrm{C} 3(P<$ $0.05)$, and no significant differences were found either between $\mathrm{C} 1$ and $\mathrm{C} 2$ or between $\mathrm{C} 4$ and $\mathrm{C} 5$.
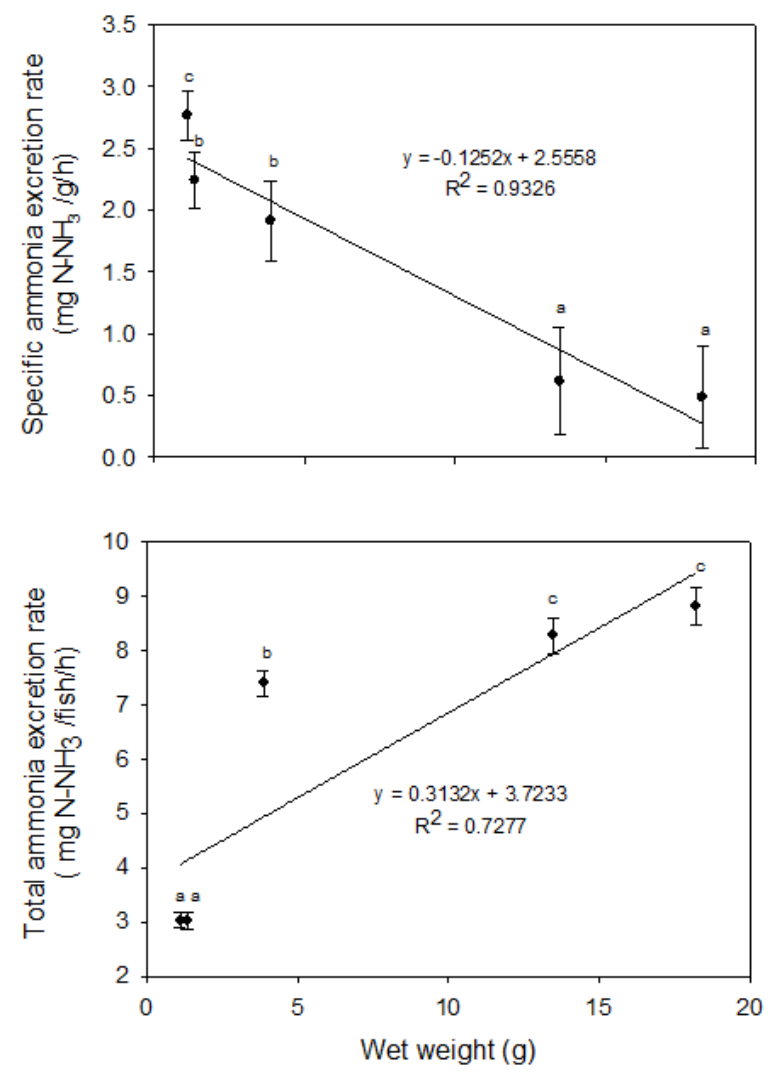

Fig2. Specific ammonia excretion rate and total ammonia excretion rate of Triplophysa yarkandensis in different size classes

\section{CONCLUSIONS}

The present study explored the routine oxygen consumption and ammonia excretion of Triplophysa yarkandensis. Both specific oxygen consumption and specific ammonia excretion reduced with the increasing of body weight. Results from present study provide reliabledata on the routine metabolic requirements of T.yarkandensis. Such data will increase the effectiveness of intensive rearing of T.yarkandensis, and the success of live fish transportation.

\section{ACKNOWLEDGEMENTS}

This project was funded by Xinjiang Production and Construction Corps Key Laboratory of Tarim Animal Husbandry Science and Technology Project (HS201010).

\section{REFERENCE}

[1] Job, S.V. 1957. The routine-active oxygen consumption of the milk fish. Proce. Indian Aca Sci. - Section B, 45: 302-313.

[2] Abdel Magid, A.M. and Babiker, M.M. 1975. Oxygen consumption and respiratory behaviour of three Nile fishes. Hydrobiologia, 46: 359-367.

[3] Brett, J.R. and Groves, T.D.D. (1979) Physiological Energetics In Fish Physiology. Bioenergetics and Growth (Hoar, W.S., et al. eds.), Vol. 8, Academic Press, New York, p. 279352.

[4] Lezama, E. and Gunther, J. 1992. The routine metabolism of the guapote, Cichlasoma managuense (Gunther 1869), related to body weight and temperature. J. Fish Biol., 41: 373-380.

[5] Zakes, Z., Demska-zakes, K., Jarocki, P. and Stawecki, K. 2005. The effect of feeding on oxygen consumption and ammonia excretion of juvenile tench Tinca tinca (L.) reared in a water recirculating sysstem. Aquacult Int, 14: 127-140.

[6] Jobling, M. (1994) Fish Bioenergetic, Chapman and Hall, London. 309pp. 
[7] Nie, Z., Wu, H., Wei, J., Zhang, X. and Ma, Z. 2013. Length-weight relationship and morphological studies in the Kashgarian loach Triplophysa yarkandensis (Day, 1877) from the Tarim River, Tarim River Basin, North-west China. Indian J. Fish., 60: 15-19.

[8] Chen, S.A., Song, Y., Zhang, M.G., Wang, Z.C. and Yao, N. 2008. Explore the fingerling production of Triplophysa yarkandensis in Tarim River Basin. J. Tar. Uni. , 2: 27-29 (Chinese Journal with English Abstract).

[9] Yuan, G.Y. (1991) Vertebrates fauna Xinjiang, Xinjiang People's Publishing, Urumqi, P.R. China. $538 \mathrm{pp}$.

[10] Forstner, H. (1983) An automated multiple-chamber intermittent-flow respirometer In Polarographic oxygen sensors: aquatic and physiological applications (Gnaiger, E. \& Forstner, H. eds.), Springer, Berlin, p. 111-116.

[11] Dalla Via, G.J. 1987. Effects of salinity and temperature on oxygen consumption in a freshwater population of Palaemonetes antenarius. Comp Biochem Physiol, 88A: 299-305.

[12] Boyd, C.E. and Tucker, C.S. (1992) Water quality and pond soil analysis for aquaculture. Alabama Agricultural Experiment Sation. Auburn University, Alabama.

[13] Beamish, F.W.H. 1974. Apparent specific dynamic action of largemouth bass Micropterus salmoides. J Fish Res Board Can, 31: 1763-1769.

[14] Alsop, D.H. and Wood, C.M. 1997. The interactive effects of feeding and exercise on oxygen consumption, swimming performance and protein usage in juvenile rainbow trout (Oncorhynchus mykiss). J. Exp. Biol., 200: 2337-2346.

[15] Smith, R.R., Rumsey, G.L. and Scott, M.L. 1978. Net energy maintenance requirements of salmonids as measured by direct calorimetry: Effect of body size and environmental temperature. J. Nutr., 108: 1017-1024.

[16] Martinez-Palacios, C.A. and Ross, L.G. 1986. The effects of temperature, body weight and hypoxia on the oxygen consumption of the Mexican majorra, Cichlasoma uropthalmus (Gunther). Aquac. Fish. Manage., 17: 243-524.

[17] Fidhiany, L. and Winckler, K. 1995. Specific oxygen consumption in two life stages of the cichlid fish Cichlasoma nigrofasciatum. Thermochim. Acta, 251: 283-291.

[18] Schmidt-Nielsen, K. (1997) Animal Physiology: Adaption and Environment, Cambridge University Press, New York. 613 pp.

[19] Fidhiany, L. and Winckler, K. 1998. Influence of body mass, age, and maturation on specid oxygen consumption in a freshwater cichlid fish, Cichlasoma nigrofasciatum (Gunther, 1869). Comp. Biochem. Physiol., 119A: 613-619.

[20] Zarski, D., Kucharczyk, D., Targonska, K., Chyla, B. and Dobrolowicz, A. 2008. Dynamics of changes in nitrogen and phosphorus compounds during intensive culture of ide Leuciscus idus (L.) in a recirculating system. Arch. Pol. Fish, 16: 459-467.

[21] Zarski, D., Kucharczyk, D., Targonska, K., Krejszeff, S., Czarkowski, T., Babiarz, E. and Nowosielska, D.B. 2010. Dynamics of nitrogen and phosphorus in closed and semi-closed recirculating aquaculture systems during the intensive culture of goldfish, Carassius auratus auratus (L.), juveniles. Arch. Pol. Fish, 18: 187-193. 